\title{
The use of the game Magic: The Gathering in the teaching of $\mathrm{L} 2$ reading $O$ uso do jogo "Magic: The Gathering" no ensino de leitura em L2
}

Raimundo Nonato de Sousa Filho', Lêda Maria Braga Tomitch²

Mestrando do Programa de Pós-Graduação em ários da UFSC

2 Doutora em Letras-Inglês, com pós-doutorado na área de neurociências pela Universidade de Carnegie Mellon, nos Estados Unidos. Professola titular do Departamento de Lingua e Literatura Estrángeiras da UFSC. Inersa-se por estudos aspectos cognitivos e instrucionais da leitura: E-mail: leda@cce.ufsc.br
ABSTRACT: The present study aimed at exploring how the Trading Card Game (TCG) 'Magic: The Gathering' (MTG) can be used in the teaching of L2 reading. More specifically, how MTG can nurture the activation of the reading processes such as decoding, literal comprehension, inferential comprehension, and comprehension monitoring. Concerning the method applied in this study, a selection of MTG cards from a recent MTG collection entitled Kaladesh was made. Furthermore, for the analysis, it was taken into consideration that the readers, thought of in this study, were MTC players rather than non-players, since the lack of schemata for the game might compromise the execution of higher reading processes. In addition, the analysis was based on the model of reading processes by Gagné et al. (1993), and its procedures consisted of explaining how the texts in the cards could trigger the execution of the reading processes. As a result, the analysis suggested that MTG indeed has potential to foster the activation of the reading processes as the cards contain texts in the form of instructions and or effects which are authentic forms of input. This input, in turn, requires the reader-player's declarative knowledge in the L2 and in MTG.

Keywords: L2 reading; Magic: The Gathering; Reading processes.

RESUMO: 0 presente estudo teve como objetivo explorar de que maneiras o Trading Card Game (TCG) Magic: The Gathering (MTG) pode ser usado para o ensino de leitura em L2. Especificamente, o estudo aborda como o MTG pode nortear a ativação dos processos de leitura como decodificação, compreensão literal, compreensão inferencial e monitoramento da compreensão. Em relação ao método aplicado nesse estudo, foi feita uma seleção de cartas de MTG de uma coleção lançada recentemente chamada Kaladesh. Ademais, para a análise, foi levado em consideração o fato de os prováveis leitores serem jogadores de MTG em contraposição a não jogadores, já que a falta de Schemata para o jogo pode comprometer a execução de processos de leitura mais complexos. Além disso, a análise foi baseada no modelo de processos de leitura de Gagné et al. (1993), e os procedimentos de análise consistiram na explicação de como os textos nas cartas podem desencadear a execução dos processos de leitura. Como resultado, a análise sugere que o MTG de fato possui potencial para fomentar a execução dos processos de leitura já que as cartas contêm textos na forma de instruções e ou efeitos, os quais são formas autênticas de insumo. Este insumo, todavia, demanda o conhecimento declarativo dos jogadores leitores, tanto em L2 quanto em MTG.

Palavras-chave: Leitura em L2; Magic: The Gathering; Processos de leitura. 


\section{Introduction}

$\mathrm{T}$ he rapid advancement of technology has resulted in a generation of people who is quite connected to new gadgets. Some researchers call them "the digital natives" (GONZÁLEZ-LLORÉT \& ORTEGA, 2014). This generation has created new demands to the classroom environment in order to adequate the activities to their realities. Another impact of the latest technological advances is the significant increase of the gamers' population (people who play digital games such as video and computer games as well as trading card games), in relation to the 1990s (HADZINSKY, 2014; Entertainment Software Association [ESA], 2015; CHIKHANI, 2015). Due to this change, games, which became considerably popular with the development of technology, are part of many people's lives, possibly impacting the way they behave and think, regardless of their age groups (KLOPFER, OSTERWEIL, GROFF, \& HAAS, 2009).

In this vein, researchers and teachers have been experimenting with the most recent pieces of technology such as computers, tablets, and cell phones in order to promote a more attractive study environment to L2 students (THOMAS \& REIDERS, 2010; GONZÁLEZ-LLORÉT \& ORTEGA, 2014). Furthermore, games have also been used for learning purposes; for example, medical courses have made use of games for the development or improvement of students' surgical precision (ROSSER JR. et al., 2007). Another example would be the use of simulator games in driving schools as a way to improve driver's abilities (LEBRAM, ENGSTRÖM, \& GUSTAVSSON, 2006). In fact, some studies have shown that the use of games may have a positive impact, such as the gain of vocabulary and motivation to learn (MILLER \& HEGELHEIMER, 2006; RANALLI, 2008; TALAK-KIRYK, 2010). Despite all the aforementioned evidence, the variety of studies involving the use of games in the teaching and learning of an L2 appears to be narrow. More specifically, there are only few studies, to our knowledge, that tackle the use of games in the teaching of reading in an L2 ${ }^{1}$ (MILLER \& HEGELHEIMER, 2006; RANALLI, 2008), which is the focus of this paper. Moreover, games do not seem to be extensively used in reading classes since most reading activities involve individual engagement as well as a silent environment, where the reader is able to concentrate on this task. Thus, games do not seem to be as popular, even though they are part of a genre that, most of the time, demands the reading ability from a superficial to a complex level. Although there have been some studies on the use of games for the teaching and learning of an L2 (MILLER \& HEGELHEIMER, 2006; RANALLI, 2008; ANDERSON, REYNOLDS, YEH, \& HUANG, 2008), no studies that tackle the issue of teaching reading in an L2 through games was found. Yet, reading is probably the language skill that could benefit the most through game playing as the large majority of games contains texts in order to give instructions or rules about the game commands, to tell a story, to explain effects, to describe characters, among other functions.

In fact, there are games that contain a considerable amount of authentic input which could be useful to the teaching of reading in an L2 since they seem to have a potential to activate the reading processes and demand reading skills and strategies. For instance, digital games of many genres, card games such as Lord of the Rings, Pokemon, Yugi-Oh, and 'Magic: The Gathering' are games which not only contain texts in the form of rules, stories, actions, effects, and conditions, but demand interpretation of the rules, inference making related to game strategies, and even planning, as discussed later in this paper. Therefore, we strongly recommend that those games can be used as reading activities in the classroom in order to promote a more attractive and fun environment for learning. With the aforementioned in mind, it is important to

By L2, we mean both second language and foreign language, in this paper. 
discuss what it means to teach reading. In general, to teach reading signifies to propose activities that foment reading processes such as decoding, literal comprehension, inferential comprehension, and comprehension monitoring. Moreover, the teaching of reading should lead to the automatization of such processes, resulting in a proficient reading (GAGNÉ et al., 1993, p. 310-311). Further elaborating, to teach reading in an L2 involves: a) strategies in order to promote vocabulary or grammatical structure learning, considering that sometimes some reading processes might not be activated because of failure in decoding, lexical access or parsing; and also b) higher level processes such as those involved in inferential comprehension.

Thus, considering the line of thought previously mentioned, the general objective of this study is to explore how the Trading Card Game (TCG) 'Magic: The Gathering2' (MTG) can be used in the teaching of $\mathrm{L} 2$ reading. More specifically, the ways in which MTG can foster the activation of the reading processes such as decoding, literal comprehension, inferential comprehension, and comprehension monitoring. The following research question will guide this study:

- How can 'Magic: The Gathering' foster the activation of the reading processes such as decoding, literal comprehension, inferential comprehension, and comprehension monitoring?

\section{Review of literature}

\subsection{Second Language Reading}

Nowadays, one cannot escape the fate of mastering the ability of reading. Being able to read seems to be quite essential in this post-modern,

\footnotetext{
A trading card game (TCG) is defined by Wizards of the Coast (MTG's developer) as a sort of game that "combines collectable cards with a strategy game".
}

globalized, and technological world which has demanded higher levels of instruction from people, not to exclude them from certain quotidian and or social activities. Similarly, and even of greater importance, reading in an L2 may signify to uncover a new world of possibilities and opportunities. However, mastering reading is not an easy task. According to Al-Mahrooqi (2014), reading is a "highly complex and interactive cognitive process" (p.viii). The author highlights that "reading is perhaps the most daunting language skill to acquire and master" (p.8) as it "involves orthographic, phonological, syntactic and semantic processing” (ALKIALBI, 2015, p.14). Moreover, as posed by Gagné et al. (1993), "skilled reading is a highly complex capability involving many component processes ${ }^{3}$ and extensive declarative knowledge ${ }^{4 \prime}$ (p. 269). Thus, Gagné et al. (1993) give an appropriate definition of what being able to read means:

Reading is a tremendously valuable basic skill. The ability to read opens up the world of jungle animals to an urban six-year old and the world of sophisticated technology to a ten-year-old villager in Ghana. It allows adults to change careers through independent study. It provides people of all ages with an inexpensive way of finding out about the variety of ideas and social and cultural landscapes that make up our world (p.268).

By relating reading to reading in an $\mathrm{L} 2$, the challenge becomes even greater, as it involves "multiple factors, including inadequate language proficiency (which slows bottom-up processing) and different or inadequate background knowledge (which hampers top-down processing)" (AL-MAHROOQI, 2014, p.viii). Therefore, it is important to think of ways to teach reading in an $\mathrm{L} 2$ which will not only motivate the use of skills,

3 Component processes refer to the reading processes which "are embodied in production sets and can be divided into decoding, literal comprehension, inferential comprehension, and comprehension

monitoring" (GAGNÉ et al., 1993, p. 267).
4 Declarative Knowledge refers to the "Knowledge about letters, phonemes, morphemes, words, ideas, schemas, and topic or subject matter" (GAGNÉ et al., 1993, p.267). 
strategies, and the execution of the reading processes, but also make the reading developmental process more attractive. Thus, following this line of thought, using games that foster the use of strategies as well as the execution of reading processes may have a significant impact on teaching reading in an $\mathrm{L} 2$.

\subsection{Reading processes}

The reading model developed by Gagné et al. (1993) concerns "three elements of expertise" which are "conceptual understanding, automated basic skills, and strategies" (p. 269). These authors explain that conceptual understanding is related to "knowledge of the topics about which one is reading, text schemas, and vocabulary" (p. 269). In the matter of automated basic skills, they are the skills related to the cognitive processes that are triggered while reading such as "decoding skills and the ability to construct propositions from strings of words" (p.269). Pertaining to strategies, Gagné et al. (1993) say that it includes "varying one's approach to reading depending upon one's goal and monitoring one's comprehension” (p. 269). Moreover, these authors point out that "conceptual understanding is housed in declarative memory" 5 while the automated basic skills and strategies are stored in procedural memory (p. 269).

In terms of decoding, it is a component reading process that operates in the word level by breaking the "code print" down into meaning (GAGNÉ et al., 1993, p.269). Inside decoding, there are two sub processes which are matching and recoding. Matching is the process in which the words are quickly recognized, as they are part of what Gagné et al. (1993) call "sight vocabulary". In this process, the "printed version of the word is directly

5 According to Laraine McDonough, Jean M. Mandler, Richard D. Mckee, and Larry R. Squire (1995),
declarative memory is "the capacity to acquire specific facts and events that are accessible to conscious recollection" (p.7580). matched to an internal, declarative representation"; as a result, "one's knowledge about the word" is activated (GAGNÉ et al., 1993). In contrast, when the reader is not able to recognize the print immediately, then recoding will be activated. In this process, before activating the meaning of the word, "the print is first translated into a string of sounds and the string of sound is then used to activate meaning" (GAGNÉ et al., 1993, p. 270). Recoding then takes place when the reader is not familiar with the vocabulary they encounter, or when the word length "exceeds the eye's perceptual span" (p. 270). To be able to access its meaning, the word is sounded out (this process occurs in one's mind). In addition, recoding "requires declarative knowledge of sub-word units such as phonemes, syllables, and morphemes" (GAGNÉ et al., 1993, p. 271).

When it comes to literal comprehension, it is a component reading process that "derives literal meaning from print", that is, it is the semantic understanding of what the print represents (p. 272). Literal comprehension involves "automated basic skills and conceptual understanding", and it is "sufficient" to cover simple reading activities such as "reading a bus schedule or reading a recipe" (p. 275). There are two processes involved in literal comprehension, which are lexical-access and parsing. In relation to lexical-access, one may say it functions similarly to a "mental dictionary" which is "accessed during language comprehension" (p. 272). According to Gagné et al. (1993), "the lexical-access process is a set of productions that uses the products of the decoding process to identify and select the appropriate word meaning". In other words, after decoding takes place by accessing the word possible meanings or representations from declarative memory, lexical-access will be responsible for selecting the "right interpretation of the word from all of the knowledge that has been activated" (p. 272). In the matter of parsing, it is a process that concerns the use of "syntactical and linguistic rules of a language to put words 
together to form meaningful ideas" (p. 272). In addition, this process has as product "propositions - units of declarative knowledge that represent the meaning of the text" (p. 273). Furthermore, it is important to mention that both lexical access and parsing operating together will "provide literal comprehension" since the first is responsible for the meaning of the words and the second is responsible for the "relations between and among words" (p. 274). However, when working individually, both processes run the risk of providing "incomplete" understanding of words and sentences (p. 274).

As previously discussed, literal comprehension is enough for the completion of certain tasks, such as reading the "bus schedule or a recipe" (GAGNÉ et al., 1993, p. 275). However, to accomplish more complex reading activities which demand more than literal comprehension, the reader needs to be able to make inferences. Thus, in this article, the concept of inferences will be in accordance with Chikalanga's (1992), Gerber and Tomtich's (2008), and Nahatame's (2015) definitions. For instance, according to Chikalanga (1992), inference is a:

Cognitive process a reader goes through to obtain the implicit meaning of a written text on the basis of two sources of information: the "propositional content of the text' (i.e. the information explicitly stated) and 'prior knowledge' of the reader (p.697).

Similarly, Nahatame defines inference as "processes through which (a) readers' relevant background knowledge is activated and (b) a subset of implicit text information is encoded in the text representation" (p.54). Furthermore, for Gerber and Tomitch (2008), inferences serve to "provide the connections which integrate the information from the text, and help the reader to build a solid mental model which gives support to comprehension, retention, and future access to the previously read information stored in memory" ${ }^{\prime \prime}$ (p. 140, our translation). Considering the different views on inferences in the field of reading comprehension, it is relevant to mention that this study draws on a perspective which considers them to refer to the semantic and pragmatic processes that are triggered in the readers' minds and serve to connect what they read to their background knowledge stored in memory, as will be discussed below.

Thus, moving to inferential comprehension, according to Gagné et al. (1993), it is a component reading process which, similarly to literal comprehension, involves "automated skills" and "conceptual understanding"; however, it also includes "strategies" (p.275). Inferential comprehension permits the reader to accomplish a more profound reading task. For instance, inferential comprehension involves relating pronouns with who or what is being talked about, and, going deeper, reading between the lines, making predictions, and even associating the ideas present in a text with ideas read in another one. Gagné et al's (1993) model organize inferential comprehension into three processes, "integration, summarization, and elaboration" (p. 275). The first concept "results in a coherent declarative representation of the ideas in the text", in other words, it accounts for the integration of "two or more propositions together" (p.275). As a result, this process "might occur within complex sentences, across sentences, and even across paragraphs" (p.275). The second concept, summarization, is responsible for generating a "macro structure" containing the main idea of the text, in the "reader's declarative memory" (p. 275). According to Gagné et al. (1993), a macro structure may be a "mental outline" formed by a group of "hierarchically arranged propositions that capture the main ideas of a passage" (p.275). In addition, it is important to state that as integration,

6 Translation of “(...) provem as conexões que integram as informações advindas do texto, levando o leitor à construção de um modelo mental sólido, que o auxilia na compreensão, na retenção e no acesso futuro à memória das informações lidas" (p. 140) 
summarization results in an "inferential product" in opposition to "literal comprehension" (275). That is, it draws the main ideas of entire passages and integrates these main ideas' meanings. The third concept, elaboration, brings "prior knowledge" in order to support the "coherent meaning representations" (p. 278) that are built by integration and summarization. In this process, one uses "pre-existing prior knowledge to add to the new ideas gleaned from the text" (p.278). In other words, elaboration permits the readers to think about examples related to the topic of the text, add a continuation, provide details, and make analogies. For instance, in the sentence "The bear walked toward John. He ran" the reader can make an elaborative inference that results in the understanding that John ran because he knows a bear is a dangerous animal that can kill a human being, and John was afraid of it (p.275).

In relation to comprehension monitoring, it is a component reading process which consists of a "mix of automated skills and strategies" that accounts for "effective and efficient" goal accomplishment, that is, its function lays on checking if the objectives, which have been set, are being met. Thus, this component process will activate the adequate processes according to the situation in question. For instance, if the objective is not being fulfilled, the initial strategy will be abandoned and a different process will be activated in order to accomplish the goal (GAGNÉ et al., 1993, p. 279). There are four different processes involved in comprehension monitoring, "goal setting, strategy selection, goal checking, and remediation" (p. 279). Concerning goal setting and strategy selection, they take place prior to the reading task itself as the reader, especially in the case of "skilled readers", selects a strategy or a set of strategies in order to reach the objective (p.279). Regarding goal checking and remediation, the first has to do with the verification of the objective, which is related to the comprehension of the reading task. When goal checking reveals some failure in comprehension, the remediation process is activated and takes care of what has disrupted comprehension (p. 279).

To sum up, according to Gagné et al's (1993) model, there are four component reading processes which are decoding, literal comprehension, inferential comprehension, and comprehension monitoring. These component processes have subprocesses, for instance, decoding involves matching and recoding, literal comprehension involves lexical access and parsing, inferential comprehension involves integration, summarization, and elaboration; and comprehension monitoring involves goal setting, strategy selection, goal checking, and remediation. All of these component subprocesses might occur individually or in parallel, depending on the input a reader receives. For instance, decoding has two subprocesses, matching and recoding, thus, if a reader cracks a word code through matching the printed word to a representation in memory, recoding will not be activated, as advocated by Gagné et al. In contrast, when matching fails, recoding is triggered in an attempt to provide word recognition through sounding out the target. Furthermore, the longer and more complex the input is, the greater is the chance of activating various processes at the same time, depending of the reader's reading proficiency, as long as it does not overload one's attentional resources. For example, when a proficient reader reads a scientific article both lower level processes (decoding and literal comprehension) and higher level ones (inferential comprehension and comprehension monitoring) may take place simultaneously or in parallel. However, while processes such as decoding and literal comprehension will most likely happen automatically, inferential comprehension and comprehension monitoring might happen in a more controlled way.

The following scheme (Figure 1) was added in order to illustrate the reading processes according to Gagné et al. (1993) in a more concise way: 
Figure 1 - Reading processes scheme

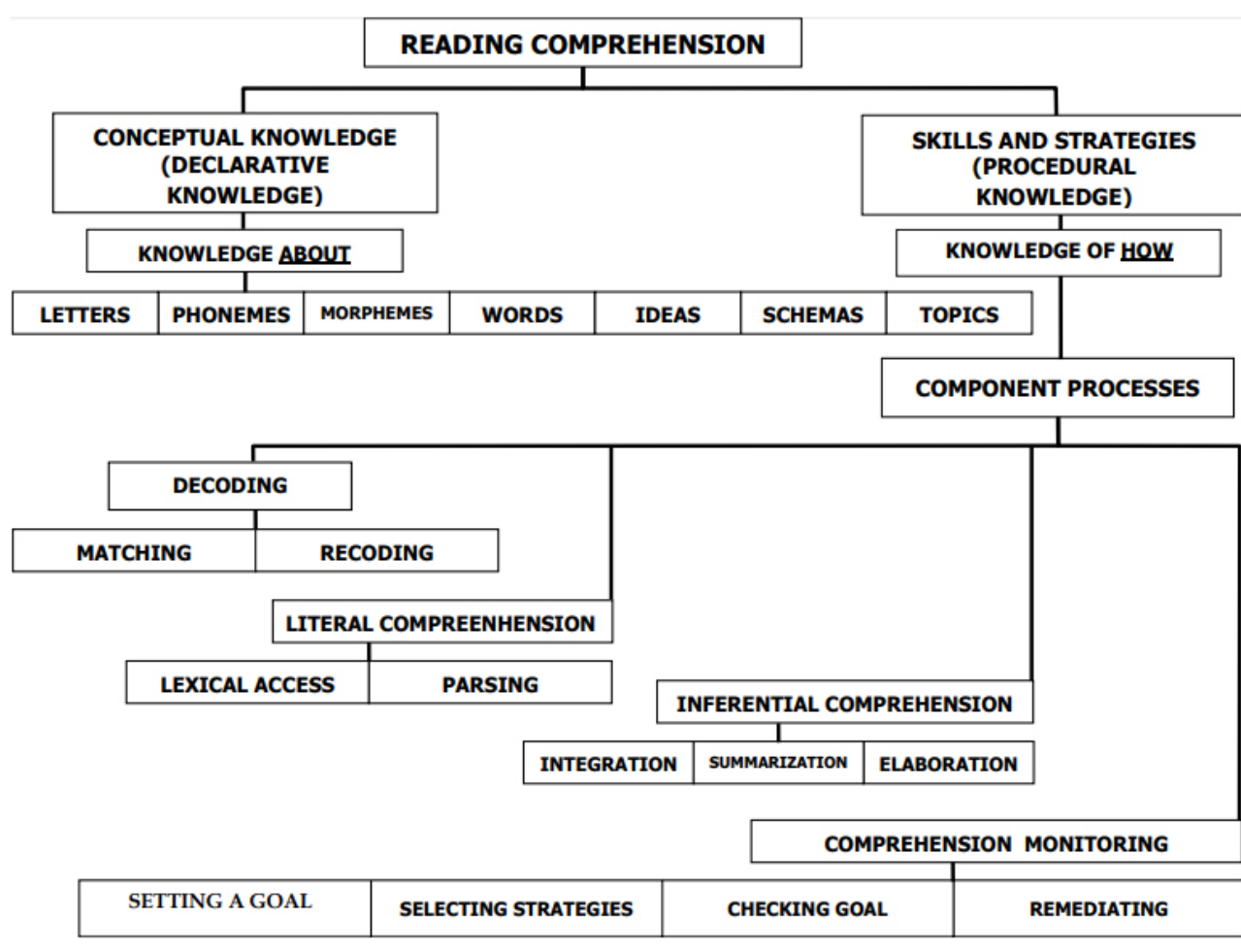

Based on GAGNÉ, E. D., YEKOVICH, C. W., \& YEKOVICH, F. R.. The cognitive psychology of school learning. Ch. 12: Reading (p. 267-312). New York: Harper Collins College Publishers, 1993.

Diagram constructed and translated by Tomitch, published in Portuguese in TOMITCH, L. M. B. Pesquisas sobre os aspectos cognitivos da leitura: 40 anos de PPGI. In: FUNCK, S. B. História e memória; 40 anos do PPGI da UFSC. Florianópolis, SC: UFSC-CCE-PPGI, 2011

\subsection{Empirical studies on games for $\mathbf{L} 2$ teaching}

As mentioned previously, there are few studies related to the use of games for teaching English as an L2. With that in mind, two of them will be reported in order to contribute to a better understanding of the area. To start with, in 2006, Megan Miller and Volker Hegelheimer adapted the best-selling, very famous and popular simulator game 'The Sims' to conduct research on ESL, more specifically, on the acquisition of vocabulary. 'The Sims' is a game that simulates real life, that is, in this game's universe, players do activities that people normally do in their quotidian as finding a job, working, buying a house, starting a family. Miller and Volker developed a framework (see MILLER \& VOLKER, 2006) in order to demonstrate how the original game, which was developed for commercial and entertainment ends, could be adapted for pedagogical purposes. There were 18 ESL students as participants who were speakers of various languages. They were organized in 6 groups of three and each group would work in two different computers, being one for the game play and the other for accessing the supplementary materials. As indicated by the results, there were significant statistical results pointing towards increase in vocabulary acquisition. In addition, the supplementary materials had a positive impact on the completion of the tasks, as suggested by the participants' feedback. Thirdly, as indicated by the results, "supplemental materials used for an authentic computer simulation task do affect task effectiveness" (MILLER \& VOLKER, 2006, p. 321).

Concerning the second study, Ranalli (2008) replicated Miller and Volker's (2006) study with the purpose of exploring whether 'The Sims' would be pedagogically beneficial to university level ESL learners, thus attaining the similar results in relation to the previous study he was replicating. Ranalli used supplementary materials and adapted the 'The Sims' to make it accessible to ESL learners in order to observe the possibility of vocabulary learning. The adaptation followed Miller and Volker's (2006) framework (see MILLER \& VOLKER, 2006). Thirdly, Ranalli conducted a qualitative analysis to obtain students' perceptions on whether they would 
enjoy the game and perceive it as a useful tool for language learning. Thus, in order to explore those objectives, Ranalli (p.6) posed the following three research questions:

1. Does structured play of the computer simulation game The Sims facilitated by the use of supplementary materials lead to vocabulary acquisition?

2. How do the participants respond to the supplementary materials and modified mode of play?

3. Do participants enjoy playing the game and perceive it as useful for language learning?

Ranalli's findings were in line with, and therefore, supported Miller and Hegelheimer' (2006) previous study. Regarding the first research question, there were statistically significant gains concerning the impact the supplementary materials and the game playing itself had in the quiz results. Thus, as the results suggested, both materials in combination with the adaptation contributed to vocabulary acquisition. In relation to the second question, most participants found the materials and the adaptation, used to "render "The Sims"' in order to make it accessible to them, "useful for language learning" (p.12). They also mentioned that the supplementary materials were "clear and helpful", as well as "enjoyable and beneficial to play the game with a partner" (p.12). In general, participants reported that they enjoyed playing the game and would play it again, if they were given the chance. Although there were limitations such as the number of participants, this study "provided evidence that commercially produced computer simulation games can, with theoretical guidance, be adapted for use by ESL students" (p. 15). In addition, "supplementary ESL materials used to support such play can contribute to vocabulary acquisition" (p.15).

In a nutshell, both studies, Miller and Hegelheimer's (2006) and Ranalli's (2008) replication of the former, brought positive insights to the field of
ESL in combination with the use of games as teaching tools. In addition, these pieces of research are contributions to this emerging area that seeks to discuss the opportunity of including games as possible pedagogical tools in the classroom. Thus, enriching the teaching range of possibilities in order to reach the new generation's realities as well as making the classes more attractive to them. Both studies' findings suggested that making use of simulator games with the support of supplementary materials and rendering of the game toward pedagogical purposes may have positive impacts on language acquisition, more specifically on vocabulary learning. These results seem motivating and can serve as an invitation to more research in this area as a way to enlarge the scope of options for the classroom practice and even be embraced by the field of reading comprehension.

\section{Method}

In order to accomplish the objectives of this study, some methodological decisions were made. In relation to the object of study, the scope will be limited to cards from the most recent MTG set called Kaladesh ${ }^{7}$. This collection of cards offers 264 cards and was released in September $30^{\text {th }}$ of 2016 in paper, and October $10^{\text {th }}$ for the online version of the game (Magic: the Gathering Online - MTGO). A single set of cards was chosen instead of the entire existing card pool in order to facilitate the selection.

In the matter of the analysis, it will consist of an explanation of how the texts present in the selected cards may activate the reading processes. It is important to mention that, in this study, it will be assumed that the card's readers are MTG players rather than non-players, since not being familiar

7 The entire set card images can be viewed in the following link: <http://magic.wizards.com/pt-br/ articles/archive/card-image-gallery/kalades>. 
with the game may compromise the activation of most of the processes, as the comprehension would be limited to literal only. Furthermore, this study will be based on the reading processes according to Gagné et al's (1993) model.

\section{1 'Magic: The Gathering'}

'Magic: The Gathering' is a Trading Card Game (TCG). A TCG is defined by Wizards of the Coast (MTG's developer) as a sort of game that "combines collectable cards with a strategy game". MTG cards are available either on paper or digitally, so one can play the game face-to-face or online. Regarding how it is played, there can be two or more players and each player is the other's opponent. Each player starts the game with seven cards and will draw one per turn. In order to play the cards and understand their effects, players must read the texts on them. There are four different ways in which one can achieve the game's final objective, which is to defeat the opponent. First, a player wins when they zero their opponent's life (which normally is the amount 20 points). Another way is through a type of damage called 'infect'. The third manner is when an opponent needs to draw a card and there are zero cards on the deck. Finally, the fourth way is when a card says that "you win the game" or "your opponent loses the game". This normally happens when you accomplish a conditional requirement demanded by a card. Regarding what types of information there are on the cards, one will see illustrated cards with a name, a card type specification, and a text box where one can find the effects and or abilities of the cards plus the "flavor text", a quotation from the romance books the card set is based on. The image (Figure 2) below shows all the elements that can be found in a card with the official categories.
Figure 2 - Parts of a card

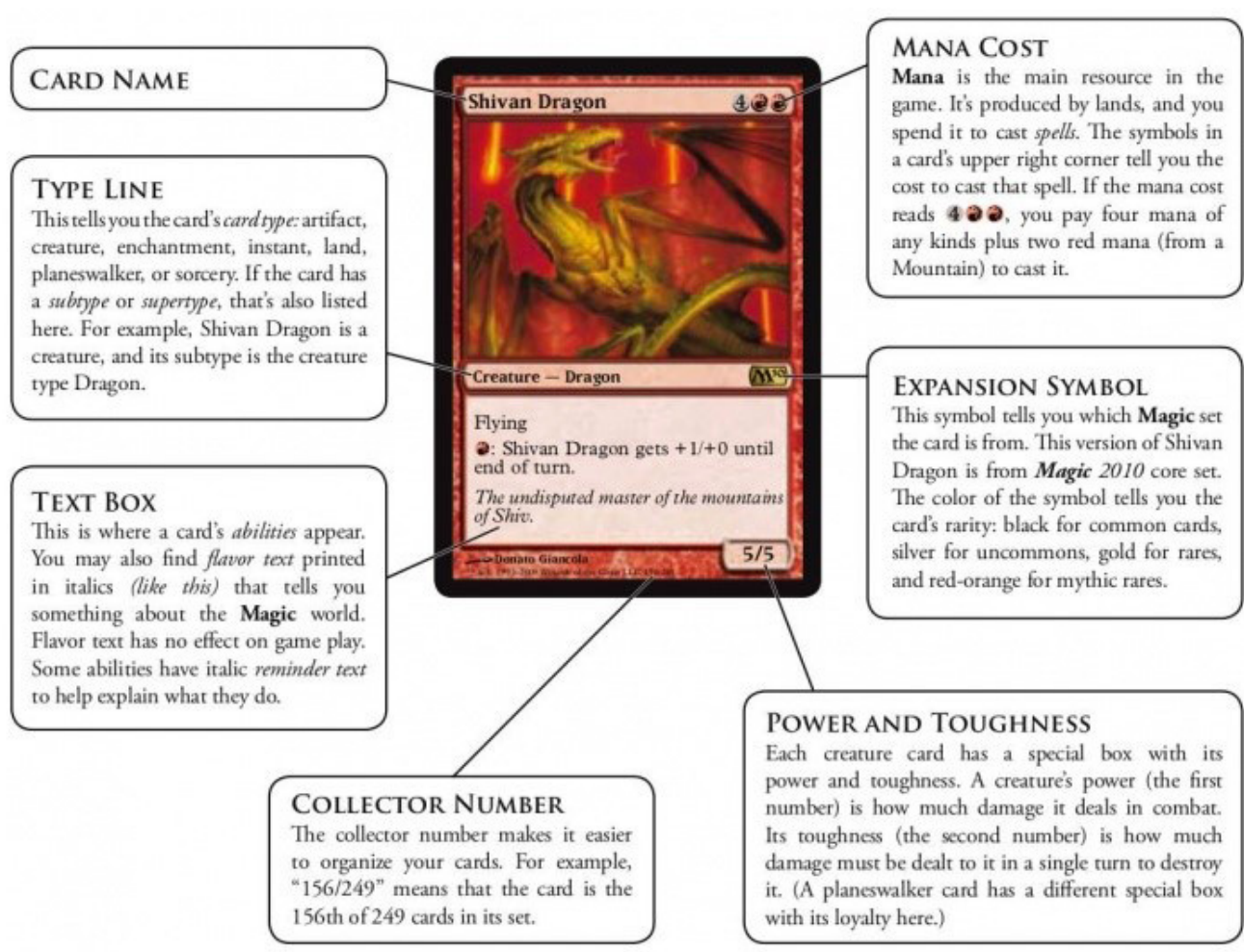

Retrieved from: <http://mtgsalvation.gamepedia.com/Parts_of_a_card>.

\section{Results and Discussion}

Considering how MTG is played and the elements one finds in a card, it is possible to say that this game not only provides authentic input in textual form, but may also engage the player in many different reading processes. Because one cannot play MTG without reading the cards, this game offers the possibility of activating the reading processes of decoding, literal 
comprehension, inferential comprehension, and comprehension monitoring. Although most of the cards will trigger decoding, some may activate either literal comprehension or inferential comprehension separately, since there are different levels of complexity in the cards' texts. To illustrate, based on Figure 3, the card named Skyswirl Harrier - a creature type card which is used for combat in the game - presents a text that is represented by a single word, Flying. Flying is a key word in the game that means that the creature with this ability can only be blocked by creatures with Flying. A player who

\section{Figure 3}

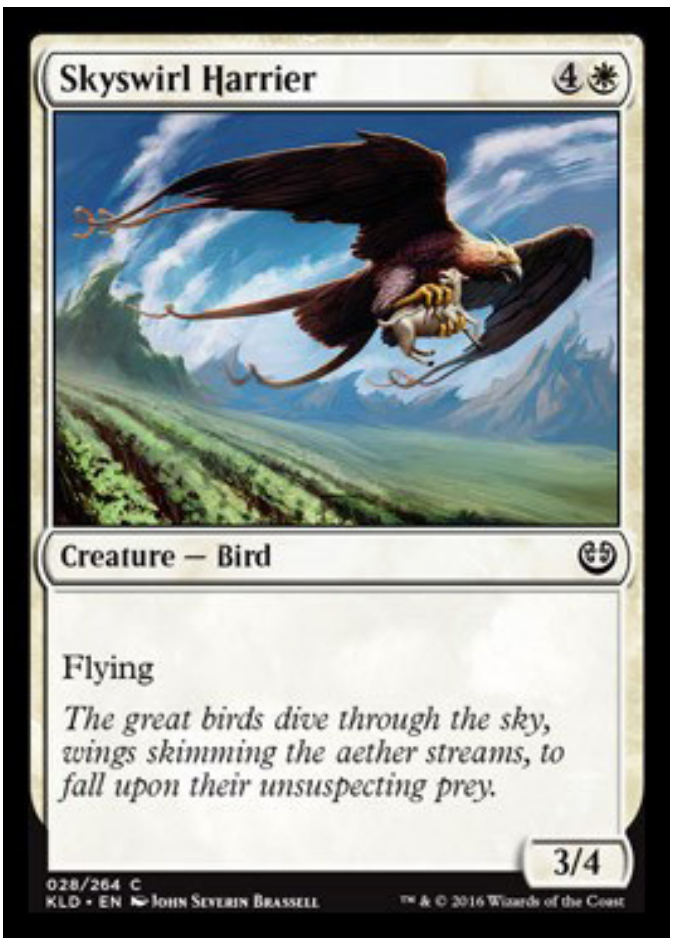

Retrieved from: <http://magic.wizards.com/en/articles/archive/card-image-gallery/kaladesh> faces this card will need decoding to crack its code as well as prior knowledge about the rules related to Flying. However, there is still the possibility that the player is not familiar with what that word represents inside the game, then, in this case, other processes will take place. For example, recoding, as the player will try to pronounce the word; goal checking and remediation, in case the meaning of the word is not accessed and the reader player needs to reestablish the goal.

When the cards contain whole sentences that explain their effects, they will not only activate decoding, but at least lexical-access. Notwithstanding, when the information present in the card is more complex, it may trigger inferential comprehension processes, considering that the sentence level may already require relating the referential elements in the sentences. In addition, the cards' interactions might require extensive prior knowledge related to the rules of the game, as well as knowledge about the cards' possibilities of interaction themselves. For instance, Figure 4 shows a card on the left that contains a somewhat straightforward effect which is "draw a card when this creature enters the battlefield". The meaning here is literal, however, when a player faces the card on Figure 5, which gives the possibility of returning a permanent card (a card on the battlefield) to this owner's hand, in order to perceive that a combination of the previous cards' effects would be advantageous, a higher level processing would take place. The advantage offered by the cards combination lies on the fact that by casting Aviary Mechanic, the player could return Nimble Innovator to its hand and cast it again, causing the player to draw an extra card. In this case, integration and elaboration will take place, since the player would have to integrate the cards' effects in order to play successfully, thus, the reader would have to access their prior knowledge (for instance, understanding the meaning of a 'permanent' in the game) in order to elaborate on the synergy of the cards. 
Figura 4

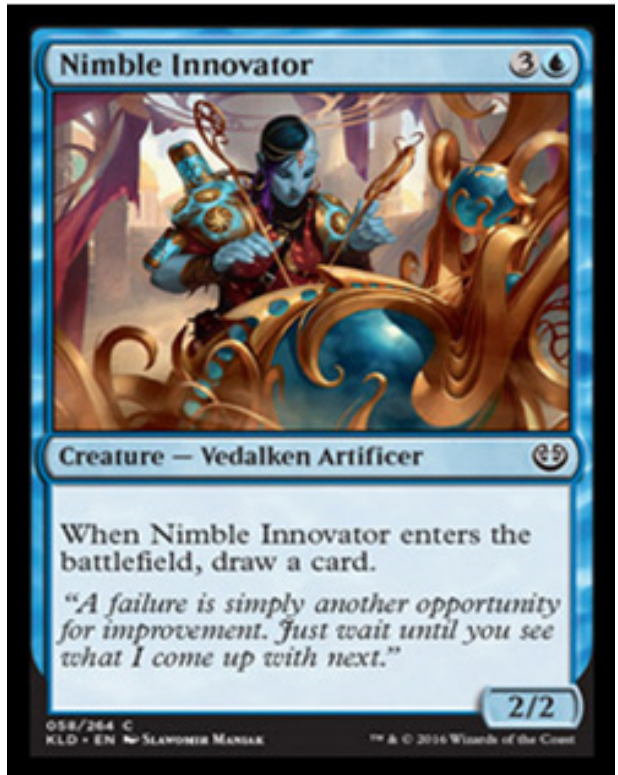

Retrieved from: <http://magic.wizards.com/en/ articles/archive/card-image-gallery/kaladesh>.
Figura 5

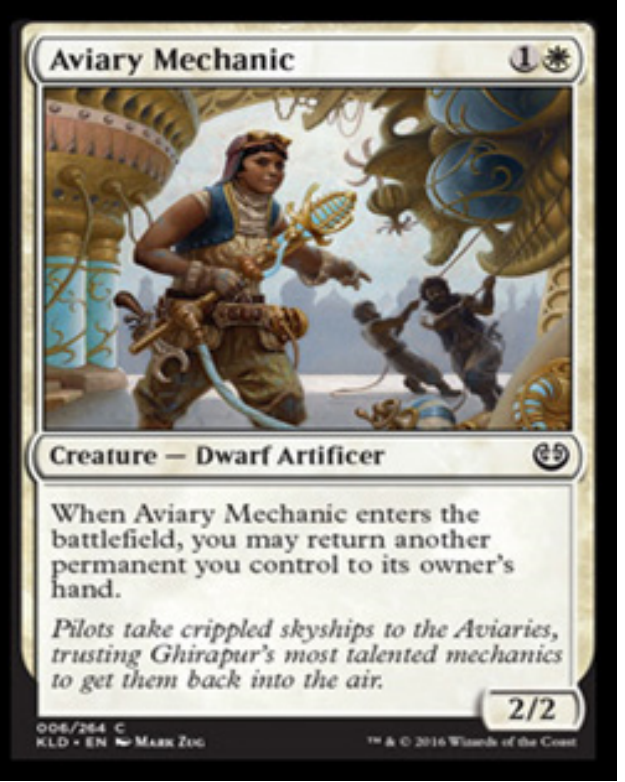

Retrieved from: <http://magic.wizards.com/en/ articles/archive/card-image-gallery/kaladesh>.
Furthermore, MTG offers even more intricate interactions between cards that demand more complex reading processes. For instance, Figure 6 presents three cards with texts that make reference to different rules of the game, and they interact with each other, creating combinations that can provide a big advantage in the game. For instance, the card Decoction Module will generate one point of energy when a creature enters the battlefield, the card Fabrication Module will put a $+1+1$ counter on target creature whenever a point of energy is received. Finally, the card Animation Module will give the option of creating a creature ${ }^{8}$ when $+1+1$ counters are placed on a creature. Thus, this combination will generate a chain of effects that will flood the battlefield with creatures with $+1+1$ counters, which may represent a big advantage in the game play. For a player to play these cards he or she will need to have a considerable amount of prior knowledge about the rules and be quite experienced in the game in order to make the possible connections between the cards and take advantage of what they offer together. In order to do so, the player will need to relate what the cards do to the rules that should be present in their long-term memory and the declarative knowledge on combining cards' effects. Considering the complex synergies of the cards, the reading processes that take place while playing the game become as complex. For instance, integration will be triggered as the reader player will have to combine the three cards' effects. In addition, elaboration will take place as the player will need to consider what the three cards can do together. However, if the player is not experienced enough or is not sufficiently skilled in reading, this possibility of taking advantage of the three cards' effects may be overlooked.

${ }^{8}$ A 'token' is a non-official card that can represent a permanent on the battlefield. Unlike the official MTC cards, a token does not have a casting cost and can be represented by dice or a piece of paper. However since July of 2007 , tokens are part of booster pack contents. 
Figure 6
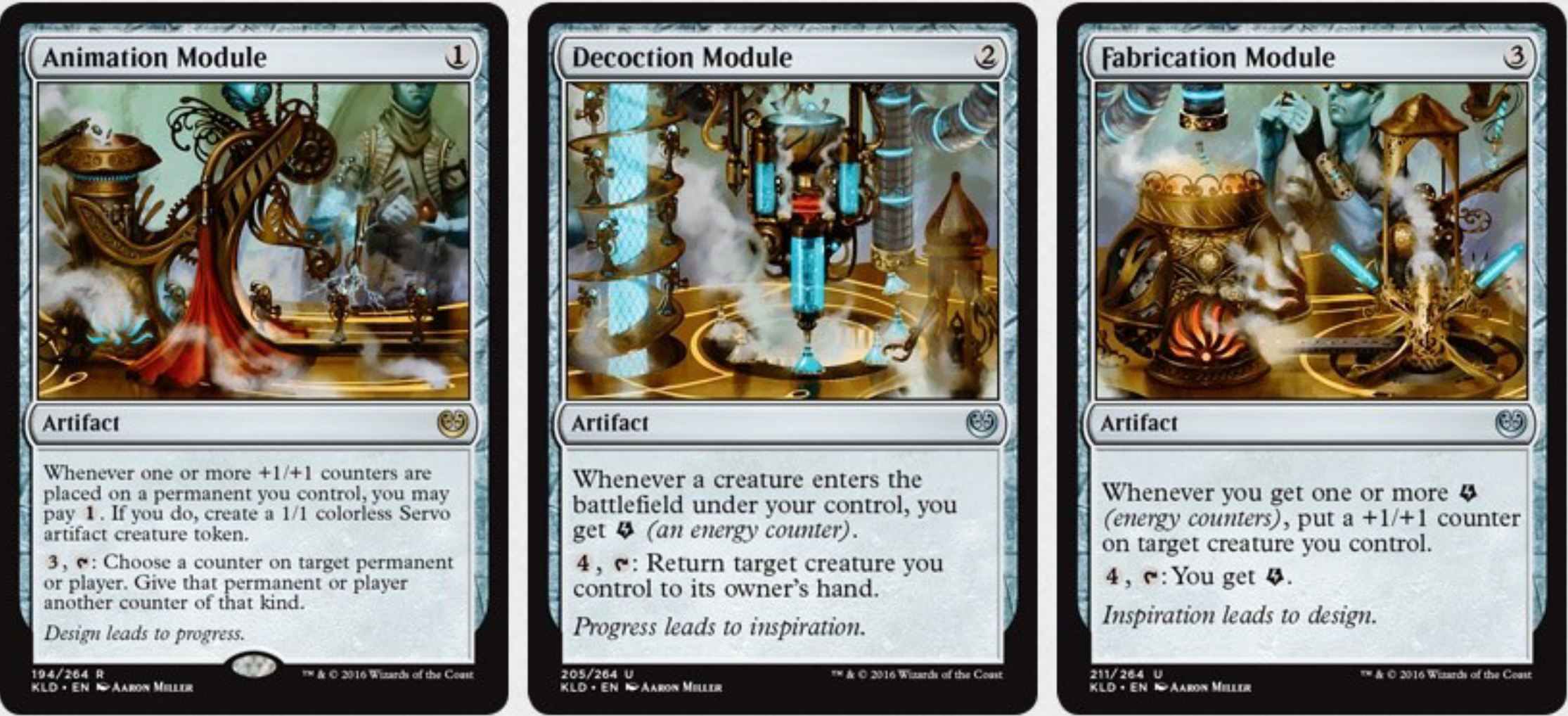

Retrieved from: <http://magic.wizards.com/en/articles/archive/card-image-gallery/kaladesh>.

Considering the possible relations between reading and playing 'Magic: The Gathering', one may argue that its cards provide authentic sources of input that can be responsible for fostering the activation of the reading processes. MTG cards vary from having a single key word until complex pieces of texts in the form of effects in the game which not only demand the knowledge about the game (schema) related to rules, but trigger both low and high reading processes such as decoding and even inferences, such as elaboration. As previously discussed, when the reader player is not familiar with the term presented in the card or does not understand what the text in the card means, then comprehension monitoring will take place in order to find a solution in the form of checking the goal and remediating in order to select another strategy to accomplish the goal. In addition, MTG cards 
can interact in a plethora of ways that challenge the players to think hard, and sometimes it will depend on a combination of their schemata about the game and how skilled they are as readers or how automatized their reading processes are.

\section{Conclusion}

In conclusion, researchers and teachers have been aware of the changes promoted by the new technologies in people's lives, especially with respect to the teaching and learning environments. Therefore, research has been done regarding the use of new gadgets as part of the classroom pedagogical tools as a way to cope with these changes. For instance, Thomas \& Reiders (2010), and González-Llorét \& Ortega (2014) discussed the inclusion of new technologies in schools' curricula. In addition, as previously mentioned, Miller \& Volker (2006), and Ranalli (2008) worked with a quite popular simulation game, 'The Sims', for vocabulary acquisition and shed some light on this emerging area of ESL and games.

As an attempt to expand the amount of studies that deal with the use of games for the teaching of reading, this paper endeavored to investigate, through a bibliographical study, how 'Magic: The Gathering', a Trading Card Game, can foster the activation of reading processes such as decoding, literal comprehension, inferential comprehension, and comprehension monitoring. As a result, the analysis suggests that MTG cards do have potential for nurturing the activation of the reading processes, as the cards not only present instructions or effects in textual form, but also demand declarative knowledge in the L2 and in the game itself. In addition, these instructions are indeed connected to the players' schemata which in turn results in the activation of the reading processes either in isolation or in parallel, when the card's context is at the sentence level and demands higher processes such as inferential comprehension. Furthermore, the cards can be combined to generate more powerful interactions and provide advantages in the game. In this case, the player will need to have a considerable amount of prior knowledge about the game in addition to the capacity of making elaborative inferences. Taking the aforementioned into consideration, one may argue that MTG can be a useful tool to foster the activation of the reading processes.

Finally, it is expected that the ideas discussed in this paper may serve as an incentive for future empirical research on the use of MTG in the SLA field, especially in reading comprehension, as a means to nurture the activation of the reading processes. In addition, research in this direction may not only contribute with this emerging and promising field, but it can also serve to test the potential this game might have for possible learners' development in the English language. Thus, this study may incentivize the development of materials for ESL courses by broadening the range of possibilities in order to make the classroom environment more dynamic and attractive to the new generations of students.

\section{References}

ANDERSON, T. A. F.; REYNOLDS, B. L.; YEH, X. P.; HUANG, G. Z. Video games in the English as a foreign language classroom. In: EISENBERG, M.; KINSHUK, M. Chang; McGREAL, $\mathrm{R}$. (Ed.). The second IEEE international conference on digital game and intelligent toy enhanced learning. 2008. p. 188-192. 10.1109/DIGITEL.2008.39

AL-KIALBI, A. The place of reading comprehension in second language acquisition. Journal of Literature, Languages and Linguistics, v. 6, p. 14-21, 2015.

AL-MAHROOQI, R.; ROSCOE, A. A. Introduction. In: AL-MAHROOQI, R.; ROSCOE, A. A. Focusing on EFL reading: Theory and practice. Newcastle upon Tyne, UK: Cambridge Scholars Publishing, 2014. p. viii-xvi.

CHIKALANGA, Israel. A suggested taxonomy of inferences for the reading teacher. Reading in a foreign language. v. 8, n. 2, p. 697-709, 1992. 
CHIKHANI, R. The history of gaming: An evolving community. 2015, October 31. Available at: <https://techcrunch.com/2015/10/31/the-history-of-gaming-an-evolvingcommunity/>. (Access: 2016 Dec. 03).

ENTERTAINMENT SOFTWARE ASSOCIATION. Essential facts about computer and video game industry. (2012) Sales Demographic and Usage Data. 2015. Available at: <http:// www.theesa.com/wp-content/uploads/2015/04/ESA-Essential-Facts-2015.pdf>.

GAGNÉ, E. D.; YEKOVICH, C. W.; YEKOVICH, F. R. The cognitive psychology of school learning. Ch. 12: Reading (p. 267-312). New York: Harper Collins College Publishers, 1993.

GERBER, R.; TOMITCH, L. Leitura e cognição: Propósitos de leitura diferentes influem na geração de inferências? Acta Scientiarum. Language and Culture, v. 30, n. 2, 2008. 10.4025/actascilangcult.v30i2.6001

GONZÁLEZ-LHORET, M,; ORTEGA, L. Technology-mediated TBLT: Researching technology and tasks. Manoa, Hawaii: John Benjamins Publishing Company, 2014.

HADZINSKY, C. A Look into the Industry of Video Games Past, Present, and Yet to Come. (Senior Theses). 2014. Available at: <http://scholarship.claremont.edu/cmc_theses/842>.

HAGEN, Å. M.; BRAASCH, J. L. G.; BRATEN, I. Relationships between spontaneous note-taking, self-reported strategies and comprehension when reading multiple texts in different task conditions. Journal of Research in Reading, v. 37, p.141-157, 2014. 10.1111/j.1467-9817.2012.01536.x

KOPFLER,E.;OSTERWEIL,S.; GROFF,J.;HAAS,J. The instructional powerofdigital games, social networking simulations and how teachers can leverage them. 2009. Available at: <http:// education.mit.edu/wp-content/uploads/2015/01/GamesSimsSocNets_EdArcade.pdf>.

LEBRAM, M.; ENGSTRÖM, H.; GUSTAVSSON, H. A Driving Simulator Based on Video Game Technology. 2006. Available at: <http://www.bing.com/cr?IG=B5047E1A8714499E80C3 6966A3668594\&CID=0DBA7E1820E6601A28C377FA21D76183\&rd=1\&h=VvNnATQT0Ic vBPnB4nfWD_mqImsdBKWArvuEDPOekB0\&v=1\&r=http://www.ep.liu.se/ecp/019/008/ ecp01908.pdf\&p=DevEx,5084.1>.

MCDONOUGH, L.; MANDLER, J. M.; MCKEE, R. D.; SQUIRE, L. R.. The deferred imitation task as a nonverbal measure of declarative memory. Proceedings of the National Academy of Sciences, v. 92, n. 16, p. 7580-7584, 1995.

MILLER, M.; HEGELHEIMER, V. The SIMs meet ESL: Incorporating authentic computer simulation games into the language classroom. Interactive technology and smart education, v. 3, n. 4, p. 311-328, 2006. 10.1108/17415650680000070
MOHEBBI, Z.; MOHEBBI, H. Unpacking the black box of lexical inferencing: briefing the factors affecting L2 learners' lexical inferencing. Advances in Social Sciences Research Journal, v. 1, n. 5, p. 22-28, 2014. Available at: <http://scholarpublishing.org/index.php/ ASSRJ/article/view/241>.

NAHATAME, S. Strategic processing and predictive inference generation in L2 reading. Reading in a Foreign Language, v. 26, n. 2, p. 54-77, 2014.

RANALLI, J. Learning English with The Sims: exploiting authentic computer simulation games for L2. Computer Assisted Language Learning, v. 21, n. 5, p. 441-455, 2008. Available at: <http://www.tandf.com/10.1080/09588220802447859>.

ROSSER, J. C.; LYNCH, P.J.; CUDDIHY, L.; GENTILE, D. A. The impact of video games on training surgeons in the 21st century. Archives of surgery, v. 142, n. 2, p.181, 2007. 10.1001/archsurg.142.2.181

TALAK-KIRYK, A. Using games in a foreign language classroom. MA TESOL Collection. Paper 484. 2010.

THOMAS, M.; REINDERS, H. Task-based language learning and teaching with technology. London, UK: Continuum, 2010.

Recebido em 24/01/2017. Aceito em 18/07/2017. 